\title{
Thermodynamics, adsorption, and response surface methodology investigation of the corrosion inhibition of aluminum by Terminalia chebula Ritz. extract in $\mathrm{H}_{3} \mathrm{PO}_{4}$
}

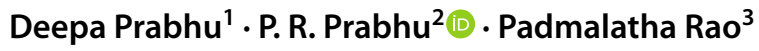

Received: 27 May 2020 / Accepted: 11 August 2020 / Published online: 31 August 2020

(c) The Author(s) 2020

\begin{abstract}
This study focuses on investigating the effect of Terminalia chebula Ritz. extract (TCE) for corrosion inhibition of $\mathrm{Al}$ in phosphoric acid $\left(\mathrm{H}_{3} \mathrm{PO}_{4}\right)$ using potentiodynamic polarization (PDP) technique. In this study, the effect of concentration of TCE extract, the concentration of $\mathrm{H}_{3} \mathrm{PO}_{4}$ acid medium, and temperature $(T)$ was investigated on the corrosion current density $\left(i_{\text {corr }}\right)$ and inhibition efficiency (IE). The TCE was characterized by FTIR analysis, and the adsorption of TCE was justified with the help of kinetic, thermodynamic, adsorption isotherm parameters. The surface morphology study was done using scanning electron microscopy (SEM), energy-dispersive X-ray spectroscopy (EDXS), and atomic force microscopy (AFM). The study also focuses on identifying the optimum process parameters for obtaining the maximum IE by applying the response surface methodology (RSM) and desirability function approach. The maximum IE of $83.24 \%$ was achieved at a temperature of $30{ }^{\circ} \mathrm{C}$, the concentration of TCE extract of $500 \mathrm{ppm}$, and $\mathrm{H}_{3} \mathrm{PO}_{4}$ acid concentration of $0.5 \mathrm{M}$. Regression analysis, Pareto chart, normal chart, main effect, and interaction effect plots are employed to acquire an in-depth understanding of process variables on IE. The IE obtained from the experiments and the predicted model is in a close match and a high value of the coefficient of determination $\left(R^{2}=99.98 \%\right)$ displays that the generated model was able to estimate the IE accurately from the selected process variables.
\end{abstract}

Keywords Aluminum · Terminalia chebula Ritz. extract · FTIR · PDP · Surface morphology $\cdot$ RSM

\section{Introduction}

Mild steel and aluminum are the two most commonly used material as it is easily available and at a lower cost. Acid solutions are commonly used in industry where hydrochloric, sulfuric acid, and phosphoric acids are the mostly used to remove the metal oxides that are formed on the surface of metals (Solomon et al. 2010; Yüce 2020; Santos et al. 2020).

P. R. Prabhu

raghu.prabhu@manipal.edu

1 Department of Chemistry, International Center for Applied Sciences, Manipal Academy of Higher Education, Manipal 576104, Karnataka, India

2 Department of Mechanical and Manufacturing Engineering, Manipal Institute of Technology, Manipal Academy of Higher Education, Manipal 576104, Karnataka, India

3 Department of Chemistry, Manipal Institute of Technology, Manipal Academy of Higher Education, Manipal 576104, Karnataka, India
Over time, the frequent use of these acid solutions may cause deterioration in metallic materials. Nowadays, the industry and the academic sectors have been interested in the use of inhibitors due to their adsorption onto the surface of the metal can reduce the corrosion rate (CR), and such adsorption depends on the physical-chemical properties of the molecules of inhibitor, the nature of metal, the aggressiveness of the corrosive medium, temperature, and electrochemical potential in the metal-solution interface (Gao and Liang 2007). On the other hand, the legislations and environmental policies enforce restrictions and the installation of residual water treatment plants as a cause of toxic inhibitors, which cause an increment in costs for industries (Fernández 1989). Those circumstances motivate the increase in developing effective and low toxicity chemical substances(Galo et al. 2020; Saxena et al. 2020; Şahin et al. 2020). Natural organic molecules such as caffeine (Fallavena, Antonow, and Gonçalves 2006), tryptamine (Moretti, Guidi, and Grion 2004; Lowmunkhong, Ungthararak, and Sutthivaiyakit 2010), and succinic acid (Giacomelli et al. 2004) have been reported 
as good inhibitors that are absorbed on the surface of metal decreasing the rate of corrosion. The majority of the ecofriendly inhibitors are normally acquired comprising nitrogen, oxygen, and sulfur as principal functional groups (D Prabhu and Rao 2013; Ferdosi Heragh and Tavakoli 2019; P. R. Prabhu, Prabhu, and Rao 2020a, b; Sedik et al. 2020; Shinato, Zewde, and Jin 2020; Chen and, Bin Zhu 2020; Benabbouha et al. 2020; Vincent Onuegbu Izionworu, Chukwuemeka Peter Ukpaka 2020; Bouhlal et al. 2020; Umoren et al. 2020). In this way, it is clear to utilize natural extracts as corrosion inhibitors for $\mathrm{Al}$ in the corrosive medium (Deepa Prabhu and Rao 2019; Mizuno, Nylund, and Olefjord 2001; Udensi, Ekpe, and Nnanna 2020; Fouda et al. 2020). There have been very few works reported on $\mathrm{H}_{3} \mathrm{PO}_{4}$ corrosive with aluminum (Li and Deng 2012; Fouda et al. 2009; Li, Deng, and Fu 2011; Fouda et al. 2012; P. R. Prabhu, Prabhu, and Rao 2020a, b).

In practice, it is a very tedious process to optimize all the process variables considered for the study to obtain the best arrangement for the enhanced performance. To interrelate the examined variables, a huge number of trials must be done to cover all the conceivable parameter mixes. This procedure is profoundly uneconomical and troublesome. The regular optimization strategies include change of one variable and keeping other variables constant. It empowers us to think about the effect of specific parameters on the whole execution of the procedure. This system is tedious and bulky, and requires an enormous number of experimental data. It is tough to get data about the related interactions of the variables in the normal technique of the optimization process (Q.K. Beg, V. Sahai 2003).

For this sort of case, statistical tools and a proper plan of experiments help to acquire data about the optimization settings. Response surface methodology (RSM) with desirability function approach (DFA) encourages the investigation of the association of a huge number of factors and their conditions with few trials prompting significant sparing in time and cost for the optimization of the process (Femiana Gapsari, Rudy Soenoko, Agus Suprapto 2018; Tansuğ et al. 2014; Ali Fakhri 2013; Demirel and Kayan 2012; Maher T, Al-Shamkhani 2018; Omoruwou F and CN 2017; P. R. Prabhu, Prabhu, and Rao 2020a, b). From the literature, it is seen that many have utilized RSM as a tool to evaluate the influence of different factors on the properties of the framework viable and to optimize the process variables which will decrease the rate of corrosion and, in this way, augment the inhibition proficiency (Asghari et al. 2016; Bingöl and Zor 2013; Jeirani et al. 2013; Sunday O. Ajeigbe, Norazah Basar 2017; Rashid and Khadom 2019). The natural inhibitor (Terminalia chebula Ritz.) used in this work is non-toxic, easily available, and environmentally friendly, and plays a unique role in the control of corrosion. The dried ripe fruits of Terminalia chebula Retz are widely used in ayurvedic medicine
(Barthakur and Arnold 1991). Fruits are drupes, glabrous, sub globose to ellipsoid, $2.5-5.0 \mathrm{~cm}$ by $1.5-2.5 \mathrm{~cm}$, usually smooth and wrinkled. Principal active ingredients of fruits of Terminalia chebula Retz. are tannins up to $30 \%$, chebulic acid 3-5\%, chebulinic acid 30\%, tannic acid $20-40 \%$, ellagic acid, 2,4-chebulyi- $\beta$-D-glucopyranose, gallic acid, ethyl gallate, etc. (Chang and Lin 2012). It is cost-effective and has distinct advantages over the chemical inhibitors which are used to control corrosion. In addition to this, the design of experiment approach has been used to minimize the number of experiments with the same level of accuracy when all the combination of experiments is conducted. Finally, we have tried to optimize the process parameters which influence the inhibition efficiency of aluminum in the phosphoric acid environment.

In this paper, the corrosion inhibition characterization of Terminalia chebula Ritz. extract on aluminum in $\mathrm{H}_{3} \mathrm{PO}_{4}$ was studied using PDP technique, and the surface measurements were carried out using SEM, EDXS, and AFM. TCE on the enhancement made to IE of $\mathrm{Al}$ in $\mathrm{H}_{3} \mathrm{PO}_{4}$ was considered using the central composite design (CCD), RSM, and DFA. This methodology of optimization of process empowers the investigation of the impact of individual variables, builds up the connection among factors and operational settings, and forecasts the exhibition at the ideal levels.

\section{Experimental}

\section{Material, medium, and inhibitor preparation}

The working electrode used for the study is the commercially obtained aluminum with the following composition: $99.61 \% \mathrm{Al}, 0.27 \% \mathrm{Fe}$, and $0.12 \% \mathrm{Si}$. The cylindrical test specimen molded in acrylic material was exposed to a corrosive medium with a surface area of $1.0 \mathrm{~cm}^{2}$. The specimen is first mechanically rubbed with sandpapers of various grades (grade 300-800), polished with a disk polishing machine to get a mirror surface finish, and then washed and dried. The experimental setup used for electrochemical measurements consists of three-electrode setups: test specimen-working electrode, the platinum electrode-counter electrode, and calomel electrode-reference electrode. $\mathrm{H}_{3} \mathrm{PO}_{4}(85 \%)$ was used for preparing the corrosive medium with different concentrations.

The extraction process is depicted in Fig. 1 and dry fruits of Terminalia chebula Ritz. (TC), and residue of the extract obtained after extraction is shown in (Fig. 2). Dried fruits of TC (Fig. 2a) were grinded well into powder. The $10 \mathrm{~g}$ of powdered TC was refluxed with $100 \mathrm{ml}$ of distilled water for $3 \mathrm{~h}$. The refluxed solution was kept overnight and filtered. Extract was heated on a water bath. After the evaporation dry dark brown powder was obtained 

tion process of Terminalia chebula Ritz. (TC)
Fig. 1 Chat representing extrac-

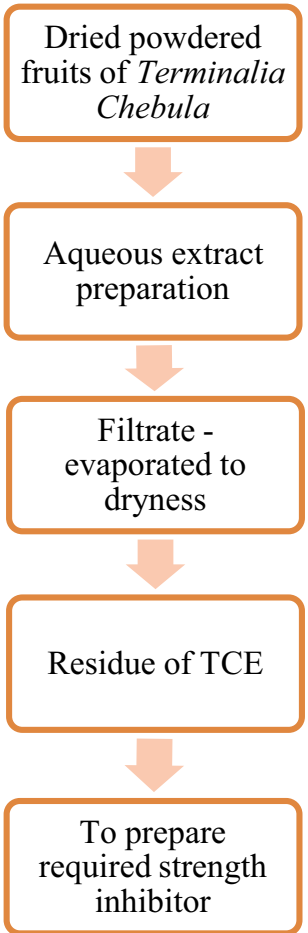

\section{Effect of temperature and kinetic factors}

The CRs were measured at several Ts $\left(30-50{ }^{\circ} \mathrm{C}\right)$ by the PDP method was utilized for the calculation of $E_{a}$ (activation energy), $\Delta H^{\#}$ (activation enthalpy), and $\Delta S^{\#}$ (activation entropy). The $E_{a}$ was determined from the Arrhenius equation, $\Delta H^{\#}$ and $\Delta S^{\#}$ were calculated using transition state equation (Deepa Prabhu and Rao 2019).

\section{Adsorption and thermodynamic factors}

The interface between the inhibitor molecule and the surface of the metal is described by adsorption isotherm. The isotherm is decided based on the correlation coefficient $\left(R^{2}\right)$ that best fits the obtained investigational data. The standard free energy of adsorption $\left(\Delta G_{a d s}^{o}\right)$ was calculated from the adsorption equilibrium constant $(K)$ (D Prabhu and Rao 2013). The plot of $\Delta G^{\circ}$ ads vs. $T$ was then used to obtain the standard enthalpy of adsorption $\left(\Delta H^{\circ}{ }_{a d s}\right)$ standard entropy of adsorption $\left(\Delta S_{a d s}^{\circ}\right)$.

\section{Surface characterization}
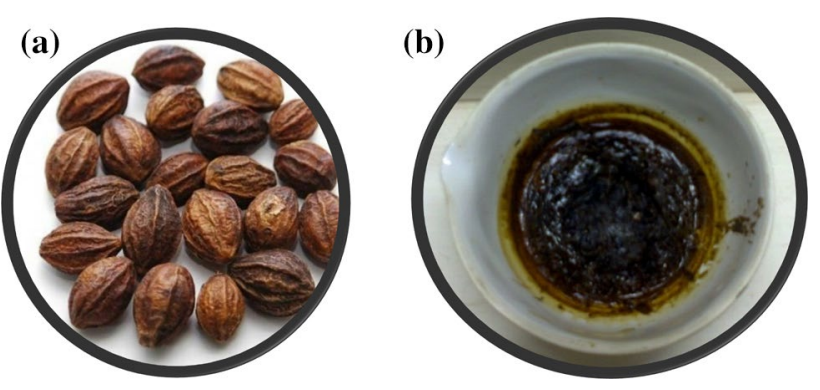

Fig. 2 a Dry seeds Terminalia chebula Ritz. b Residue of the extract obtained after extraction

(Fig. 2b). The residue of TCE obtained was then finely grinded using a mortar and pestle and stored in desiccator. Shimadzu FTIR spectrophotometer was utilized for the FTIR measurement of the inhibitor sample.

\section{Potentiodynamic polarization}

The instrument used for performing the potentiodynamic polarization measurement is an electrochemical work station of model CH600D. Polished test specimens were allowed to achieve open circuit potential (OCP). Then, the samples were polarized with the potential of $-250 \mathrm{mV}$ cathodically and $+250 \mathrm{mV}$ anodically at a scan level of $1.0 \mathrm{mVs}^{-1}$.
The surface characterizations of metal dipped in $1.0 \mathrm{M}$ $\mathrm{H}_{3} \mathrm{PO}_{4}$ solution with and without $500 \mathrm{ppm}$ TCE inhibitor were examined by capturing the images with the magnification of $1 \mathrm{~K} X$ using SEM and EDXS using EVO MA18. AFM was carried out using the instrument IB342 Innova model.

\section{Optimization of parameters for IE}

RSM with CCD was utilized for identifying the influence of temperature (A), the concentration of TCE extract (B), and concentration of acid (C) on the IE, and the interference between these variables. All three variables were taken at three levels as given below: temperature-30, 40 , and $50{ }^{\circ} \mathrm{C}$; concentration of TCE extract-100, 300, and $500 \mathrm{ppm}$; concentration of acid-0.5, 1.25, 2.0 M. A full quadratic regression model was used to find out the association between the efficacy of the inhibitor and the factors which were used for the study. The influences of various variables on the IE are accurately examined using the formula as given below (Eq. 1):

$$
\begin{aligned}
Y 1= & c_{0}+c_{1} A+c_{2} B+c_{3} C+c_{12} A B+c_{13} A C+c_{23} B C \\
& +c_{11} A^{2}+c_{22} B^{2}+c_{33} C^{2},
\end{aligned}
$$

Y1: IE predicted by the regression equation. 
$\mathrm{A}, \mathrm{B}$, and $\mathrm{C}$ : independent factors representing the temperature, concentration of TCE extract, and concentration of $\mathrm{H} 3 \mathrm{PO} 4$.

$c_{0}$ : constant, $c_{1}, c_{2}$, and $c_{3}$ : constants indicating the impact of variables $\mathrm{A}, \mathrm{B}$, and $\mathrm{C}$.

$c_{12}, c_{13}, c_{23}$ : constants indicating the collaboration between the variables $\mathrm{AB}, \mathrm{AC}, \mathrm{BC}$.

$c_{11}, c_{22}$, and $c_{33}$ : constants indicating the impact of quadratic $\mathrm{A}, \mathrm{B}$, and $\mathrm{C}$.

The examination plans to recognize the ideal parameter setting to limit the pace of corrosion and in this way to secure the maximum IE. It is hard to discover the ideal handling factors. In this way, the DOE approach was utilized to look at the effects of the various factors on the reaction. At that point, the mix of the procedure factors that can achieve an ideal foreseen worth can be obtained.

\section{Results and discussion}

\section{Inhibitor characterization}

The aqueous extract of Terminalia chebula comprises of many carbon-based compounds and the major constituents reported in the literature to be chebulinic acid and 1,2,3,4,6-pentagalloyl glucose (Chang and Lin 2012). FTIR spectrum of TCE is given in (Fig. 3).

\section{Potentiodynamic polarization}

The PDP measurements for the corrosion of $\mathrm{Al}$ were performed in different strength of $\mathrm{H}_{3} \mathrm{PO}_{4}$ and with different amounts of TCE. Figure 4 represents the PDP plots for the deterioration of $\mathrm{Al}$ in $1.0 \mathrm{M} \mathrm{H}_{3} \mathrm{PO}_{4}$ having various

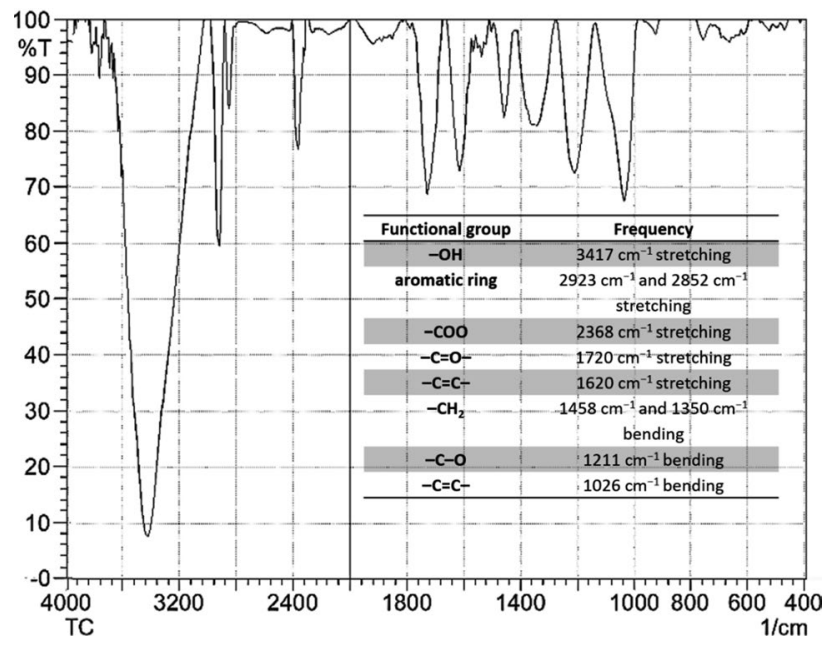

Fig. 3 FTIR spectrum of Terminalia chebula Ritz. extract solid residue

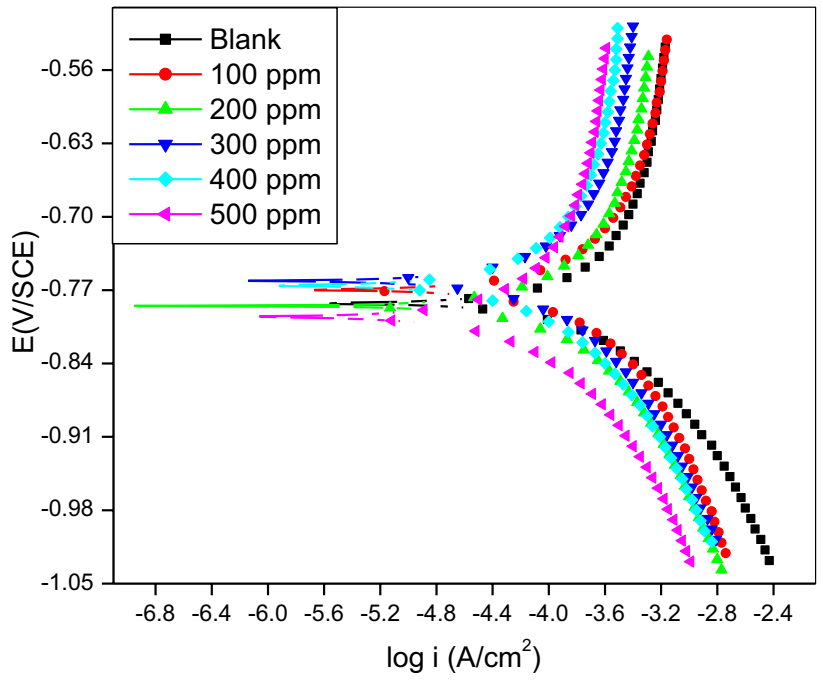

Fig. 4 Potentiodynamic polarization plots in $1.0 \mathrm{M} \mathrm{H}_{3} \mathrm{PO}_{4}$ containing different concentrations of TCE at $30{ }^{\circ} \mathrm{C}$ for the corrosion of aluminum

concentrations of TCE at $30{ }^{\circ} \mathrm{C}$. The anodic branches of the PDP plots were strongly curved (Li and Deng 2012), henceforth it was unable to obtain anodic Tafel slopes $\left(\beta_{\mathrm{a}}\right)$. For the obtained cathodic Tafel slope $\left(\beta_{\mathrm{c}}\right)$ there was no substantial variation in the values, which propose that there was no alteration in the mechanism of the cathodic process with TCE. According to Riggs, if the corrosion potential value $\left(E_{\text {corr }}\right)$ was on an average of less than $\pm 85 \mathrm{mV}$ (Nathan and of Corrosion Engineers 1973). This suggests that TCE act as a mixed type of inhibitor. Results of the PDP on Al containing TCE at $30{ }^{\circ} \mathrm{C}$ are given from Table 1 . The $i_{\text {corr }}$ values increased with an increase in the concentration of medium indicating the increased corrosion activity due to which decrease in the IE was observed.

\section{Effect of concentration of $\mathrm{H}_{3} \mathrm{PO}_{4}$, variations in temperature, and kinetic factors}

The rate of corrosion of aluminum increased with an increase in the concentration of $\mathrm{H}_{3} \mathrm{PO}_{4}$ corrosive arrangement. It is since, more is the concentration of the corrosive medium, higher will be the rate of corrosion. Since the present examination additionally targets finding the ideal concentration of inhibitor essential to acquire the highest possible IE, the various concentrations of inhibitor have been utilized in the various concentration if corrosive medium instead of utilizing the same arrangement of inhibitor.

Figure 5 characterizes the variation of the IE of TCE with $\mathrm{T}\left(30-50^{\circ} \mathrm{C}\right)$. With an increase in $T$, the IE decreased indicating physical adsorption, since the interaction is electrostatic between TCE molecules with the metal surface. 
Table 1 Results of potentiodynamic polarization for the corrosion of aluminum in different concentration of $\mathrm{H}_{3} \mathrm{PO}_{4}$ containing different concentrations of TCE at $30{ }^{\circ} \mathrm{C}$

\begin{tabular}{llllll}
\hline$\left[\mathrm{H}_{3} \mathrm{PO}_{4}\right](\mathrm{M})$ & {$[\mathrm{TCE}](\mathrm{ppm})$} & $\begin{array}{l}E_{\text {corr }}(\mathrm{mV} \text { vs. } \\
\text { SCE })\end{array}$ & $i_{\text {corr }}\left(\mathrm{mA} \mathrm{cm}^{-2}\right)$ & $\begin{array}{c}-\beta_{\mathrm{c}}(\mathrm{mV} \\
\left.\mathrm{dec}^{-1}\right)\end{array}$ & $I E(\%)$ \\
\hline 0.5 & -797 & 0.1734 & 637 & - \\
& 0.0 & -790 & 0.0617 & 625 & 64.42 \\
& 50 & -816 & 0.0559 & 602 & 67.76 \\
& 100 & -769 & 0.0467 & 677 & 73.07 \\
& 200 & -770 & 0.0379 & 655 & 78.14 \\
& 300 & -773 & 0.0290 & 617 & 83.22 \\
& 400 & -783 & 0.2587 & 674 & - \\
& 0.0 & -770 & 0.1009 & 636 & 61.00 \\
& 100 & -785 & 0.0915 & 632 & 64.64 \\
& 200 & -761 & 0.0799 & 603 & 69.09 \\
& 300 & -766 & 0.0662 & 598 & 74.40 \\
& 400 & -795 & 0.0540 & 596 & 79.11 \\
& 500 & -770 & 0.3685 & 660 & - \\
& 0.0 & -751 & 0.1505 & 634 & 59.15 \\
& 200 & -753 & 0.1389 & 616 & 62.30 \\
& 300 & -748 & 0.1186 & 610 & 67.73 \\
& 400 & -749 & 0.1019 & 594 & 72.34 \\
& 500 & -766 & 0.0809 & 590 & 78.04 \\
\hline 60 & & &
\end{tabular}

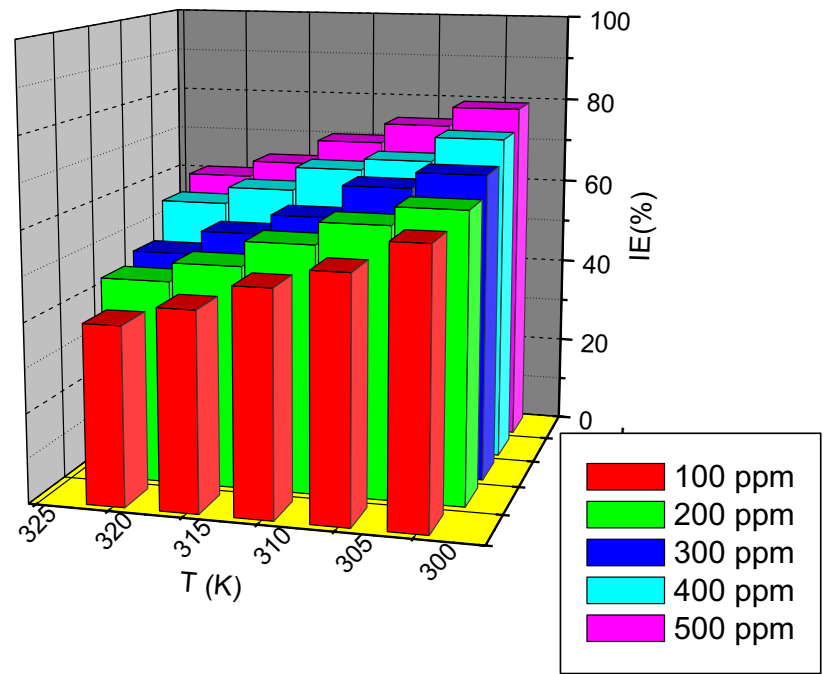

Fig. 5 Effect of temperature on inhibition efficiency with different concentration of TCE in $1.0 \mathrm{M} \mathrm{H}_{3} \mathrm{PO}_{4}$ for the corrosion of aluminum

These electrostatic forces reduce their attractive force at high temperatures.

Arrhenius plot and $\ln (C R / T)$ vs. $1 / T$ in $1.0 \mathrm{M} \mathrm{H}_{3} \mathrm{PO}_{4}$ comprising $\mathrm{TCE}$ on $\mathrm{Al}$ is given in Fig. 6. Activation factors for the deterioration of $\mathrm{Al}$ in $1.0 \mathrm{M} \mathrm{H}_{3} \mathrm{PO}_{4}$ comprising TCE are presented in Table 2. With the increase in concentrations of inhibitor, the activation energy $\left(E_{a}\right)$ increased, which directs that the energy barrier for the corrosion process increased with an increase in TCE concentration. The values of activation enthalpy $\left(\Delta H^{\#}\right)$ varied correspondingly as that of $E_{a}$, associate the suggested mechanism. The entropy activation $\left(\Delta S^{\#}\right)$ values were negative, which characterizes molecular association and decreases in disorderliness during the formation of the activated complex (Oguzie et al. 2008).

Energy of activation $\left(E_{a}\right)$ was calculated from the Arrhenius equation (Eq. 2):

$\ln (C R)=B-\frac{E_{a}}{R T}$,

where $B$ is a constant which varies from one metal type to another, $R$ is the universal gas constant $\left(8.314 \mathrm{~J} \mathrm{~mol}^{-1} \mathrm{~K}^{-1}\right)$, and $T$ is the absolute temperature. The enthalpy of activation $\left(\Delta H^{\#}\right)$ and entropy of activation $\left(\Delta S^{\#}\right)$ were calculated using transition state equation (Eq. 3):

$C R=\frac{R T}{N h} \exp \left(\frac{\Delta S^{\#}}{R}\right) \exp \left(\frac{\Delta H^{\#}}{R T}\right)$,

where $h$ is Plank's constant $\left(6.626 \times 10^{-34} \mathrm{~J} . \mathrm{s}\right), N$ is Avogadro's number $\left(6.022 \times 10^{23} \mathrm{~mol}^{-1}\right)$ and $T$ is the absolute temperature.

\section{Adsorption and thermodynamic factors}

TCE obeyed Langmuir adsorption isotherm, shown in Fig. 7a. The standard free energy of adsorption $\left(\Delta G^{\circ}{ }_{a \mathrm{ds}}\right)$ was obtained from the adsorption equilibrium constant $(K)$ (Akinbulumo, Odejobi, and Odekanle 2020). A plot of $\Delta G^{\circ}{ }_{a d s}$ versus $\mathrm{T}$ for TCE on $\mathrm{Al}$ in $1.0 \mathrm{M} \mathrm{H}_{3} \mathrm{PO}_{4}$ is given in 

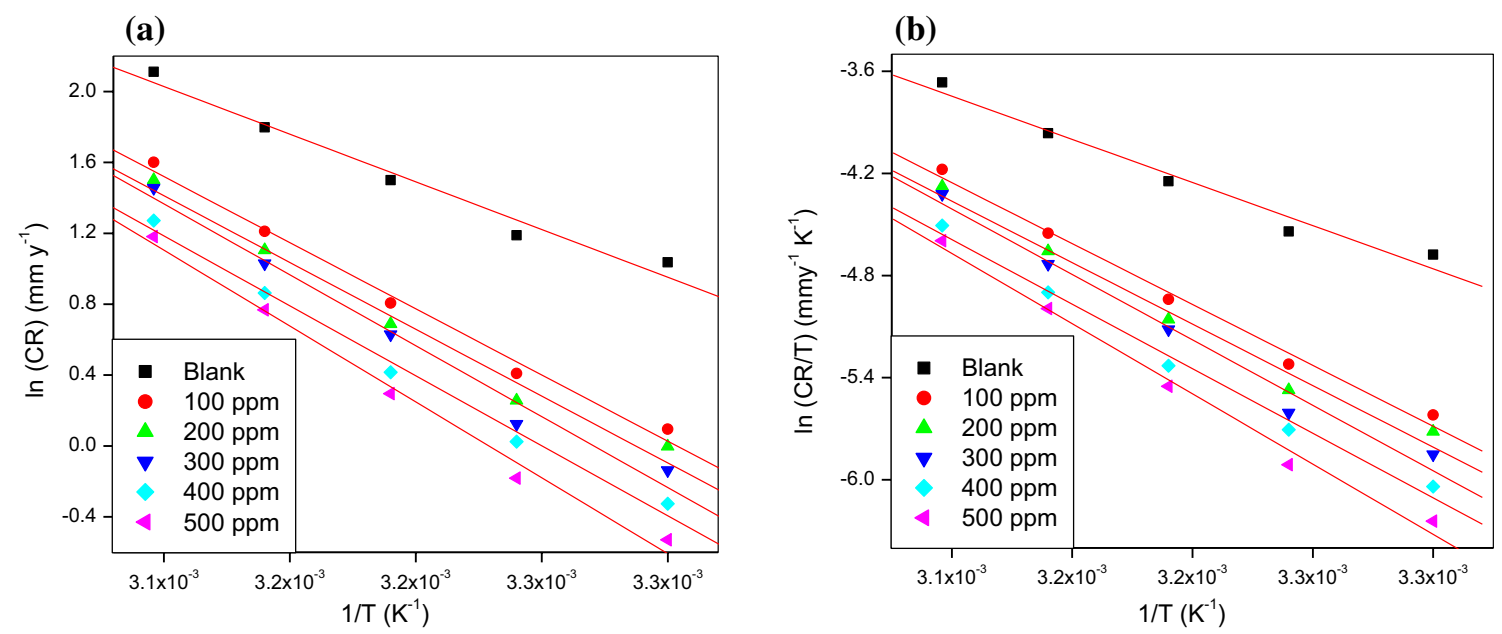

Fig. 6 a Arrhenius plot and $\mathbf{b} \ln (C R / T)$ versus $1 / T$ in $1.0 \mathrm{M} \mathrm{H}_{3} \mathrm{PO}_{4}$ with different concentrations of TCE for the corrosion of aluminum

Table 2 Activation parameters for the corrosion of aluminum in $\mathrm{H}_{3} \mathrm{PO}_{4}$ containing different concentrations of TCE

\begin{tabular}{lllll}
\hline$\left[\mathrm{H}_{3} \mathrm{PO}_{4}\right](\mathrm{M})$ & {$[\mathrm{TCE}](\mathrm{ppm})$} & $E_{a}\left(\mathrm{~kJ} \mathrm{~mol}^{-1}\right)$ & $\Delta H^{\#}\left(\mathrm{~kJ} \mathrm{~mol}^{-1}\right)$ & $\Delta S^{\#}\left(\mathrm{~J} \mathrm{~mol}^{-1} \mathrm{~K}^{-1}\right)$ \\
\hline 0.5 & 45.70 & 43.15 & -56.64 \\
& 0.0 & 61.65 & 59.04 & -54.73 \\
& 50 & 61.73 & 59.12 & -53.47 \\
& 100 & 66.03 & 63.42 & -43.17 \\
& 200 & 66.94 & 64.33 & -38.81 \\
& 300 & 74.40 & 71.80 & -17.85 \\
& 400 & 50.24 & 47.69 & -37.85 \\
1.0 & 0.0 & 62.08 & 59.47 & -48.59 \\
& 100 & 62.68 & 60.08 & -47.61 \\
& 200 & 65.67 & 63.06 & -36.07 \\
& 300 & 66.53 & 63.92 & -40.23 \\
& 400 & 71.20 & 68.59 & -23.76 \\
& 500 & 56.78 & 54.23 & -15.32 \\
& 0.0 & 63.71 & 61.11 & -40.35 \\
& 200 & 63.80 & 61.20 & -39.16 \\
& 300 & 66.43 & 63.82 & -33.76 \\
& 400 & 67.29 & 64.68 & -29.73 \\
& 500 & 72.39 & 69.78 & -15.88 \\
\hline 600 & & &
\end{tabular}

Fig. 7b. Thermodynamic factors for the TCE adsorption are given in Table 3 .

The Langmuir adsorption isotherm mathematically can be represented by the following equation (Eq. 4):

$\frac{C_{i n h}}{\theta}=C_{i n h}+\frac{1}{K}$

where $K$ is the adsorption equilibrium constant, $C_{i n h}$ is inhibitor concentrations (in ppm), and $\theta$ is the surface coverage.
From the adsorption equilibrium constant $(K)$, standard free energy of adsorption $\left(\Delta G_{a \mathrm{ds}}^{\circ}\right)$ can be calculated using the equation (Eq. 5):

$\Delta G_{a d s}^{\circ}=-R T \ln K$,

where $R$ is the universal gas constant (8.314 $\mathrm{J} \mathrm{mol}^{-1} \mathrm{~K}^{-1}$ ) and $T$ is the absolute temperature. 

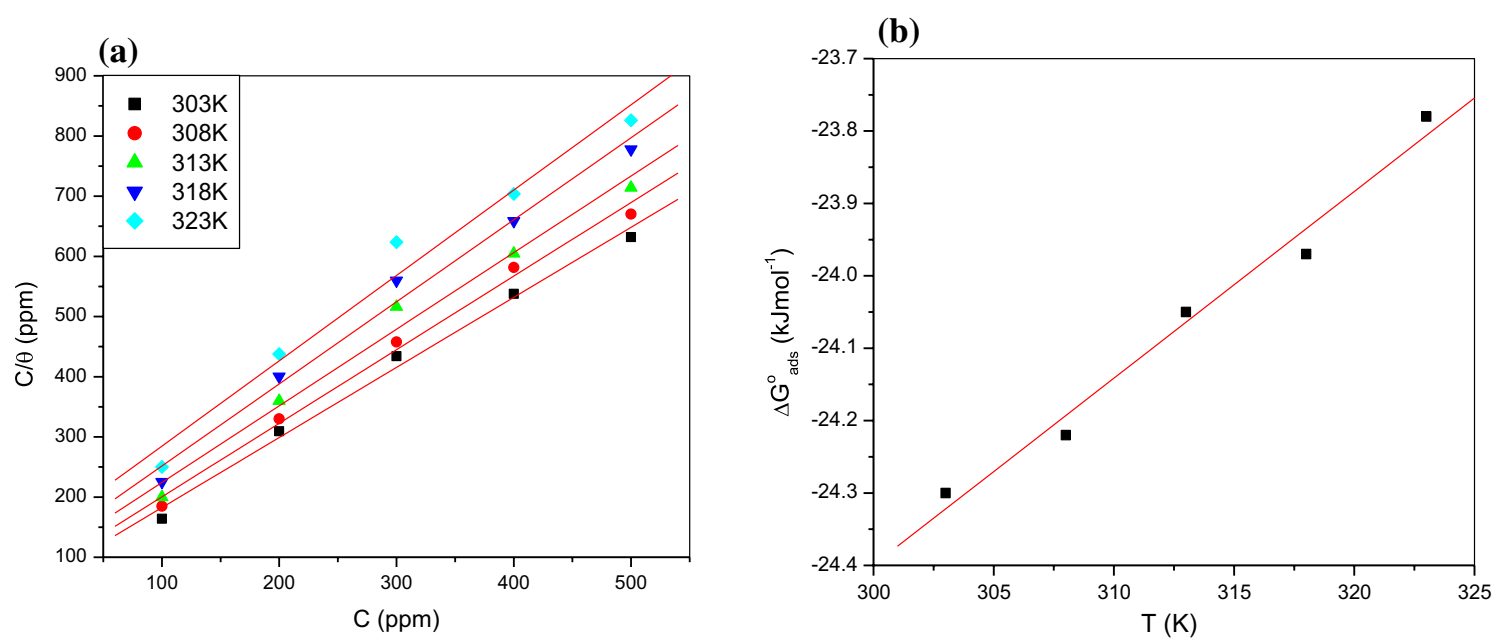

Fig. 7 a Langmuir adsorption isotherms and b Plot of $\Delta G^{\circ}$ ads versus $T$ for TCE in $1.0 \mathrm{M} \mathrm{H}_{3} \mathrm{PO}_{4}$ for the corrosion of aluminum

Table 3 Thermodynamic factors for the adsorption of TCE on aluminum in $\mathrm{H}_{3} \mathrm{PO}_{4}$ at different temperatures

\begin{tabular}{|c|c|c|c|c|}
\hline$\left[\mathrm{H}_{3} \mathrm{PO}_{4}\right](\mathrm{M})$ & $T(K)$ & $\begin{array}{l}\Delta \mathrm{G}_{\text {ads }}^{\mathrm{o}} \\
\left(\mathrm{kJ} \mathrm{mol}^{-1}\right)\end{array}$ & $\begin{array}{l}\Delta \mathrm{H}_{\mathrm{ads}}^{\mathrm{o}} \\
\left(\mathrm{kJ} \mathrm{mol}^{-1}\right)\end{array}$ & $\begin{array}{l}\Delta \mathrm{S}_{\text {ads }}^{\mathrm{o}} \\
\left(\mathrm{J} \mathrm{mol}^{-1} \mathrm{~K}^{-1}\right)\end{array}$ \\
\hline \multirow[t]{5}{*}{0.5} & 303 & -22.90 & \multirow[t]{5}{*}{-49.41} & \multirow[t]{5}{*}{-87.32} \\
\hline & 308 & -22.56 & & \\
\hline & 313 & -22.13 & & \\
\hline & 318 & -21.68 & & \\
\hline & 323 & -21.16 & & \\
\hline \multirow[t]{5}{*}{1.0} & 303 & -22.86 & \multirow[t]{5}{*}{-31.44} & \multirow[t]{5}{*}{-28.53} \\
\hline & 308 & -22.71 & & \\
\hline & 313 & -22.52 & & \\
\hline & 318 & -22.42 & & \\
\hline & 323 & -22.20 & & \\
\hline \multirow[t]{5}{*}{2.0} & 303 & -16.72 & \multirow[t]{5}{*}{-46.71} & \multirow[t]{5}{*}{-98.56} \\
\hline & 308 & -16.46 & & \\
\hline & 313 & -15.92 & & \\
\hline & 318 & -15.42 & & \\
\hline & 323 & -14.78 & & \\
\hline
\end{tabular}

Standard enthalpy of adsorption $\left(\Delta H^{\circ}{ }_{a d s}\right)$ and standard entropy of adsorption $\left(\Delta S_{a d s}^{\circ}\right.$ ) can be calculated from equation (Eq. 6):

$\Delta G_{a d s}^{\circ}=\Delta H_{a d s}^{\circ}-T \Delta S_{a d s}^{\circ}$

With TCE as an inhibitor, the $\Delta G^{\circ}$ ads were close to -20 $\mathrm{kJ} \mathrm{mol}^{-1}$ (Galo et al. 2020) and the value increased with the increase in $T$. This suggests physical adsorption of TCE on the surface of $\mathrm{Al}$ (Fouda et al. 2009). The adsorption enthalpy $\left(\Delta H^{\circ}\right.$ ads $)$ was negative, which is the indication of the exothermic process, which additionally confirms physisorption. The entropy of adsorption $\left(\Delta S_{a d s}^{\circ}\right)$ was large and negative, indicating the orderly arrangement of inhibitor molecules on the surface) (Tang, Mu, and Liu 2003).

\section{Surface characterization}

\section{SEM and EDXS analysis}

The SEM and EDXS pictures of $\mathrm{Al}$ in $1.0 \mathrm{M}$ phosphoric corrosive are given in Fig. 8. Within the sight of $1.0 \mathrm{M}$ $\mathrm{H}_{3} \mathrm{PO}_{4}$ metal surface, it is seen from Fig. 8a that the surface is rough with the deposition of corrosion products on the surface of the metal. The corresponding EDXS investigation validates the existence of $\mathrm{Al}$ oxides on the surface of the metal, the composition on the surface at this stage consists of aluminum ( $84.18 \%)$, oxygen $(14.76 \%)$, and phosphorous (1.06\%). EDXS analysis can be ascribed to the contact of the metal with the corrosive medium as it consists of phosphorus peak.

The SEM and EDXS pictures of $\mathrm{Al}$ in $1.0 \mathrm{M}$ phosphoric corrosive in $500 \mathrm{ppm}$ of TCE are given in Fig. 9. The surface turned out to be smooth and uniform with the inclusion of the inhibitor. There was the construction of inhibitor film above the surface of metal due to the adsorption of protective species. Uniform and reduced surface film legitimize the adsorption of the inhibitor atom on the outside of the metal. EDXS inspection showed a drop in the ingredient of aluminum ( $80.90 \%)$, oxygen $(5.44 \%)$, and phosphorous (0.50\%). The carbon peak (14.21\%) confirms the adsorption of TCE on Al.

\section{AFM analysis}

The 3-D AFM method is a method for exploring the surface topography at the micro- and nano-levels. The 3-D images of Al with and without TCE are given in Fig. 10. 
(a)

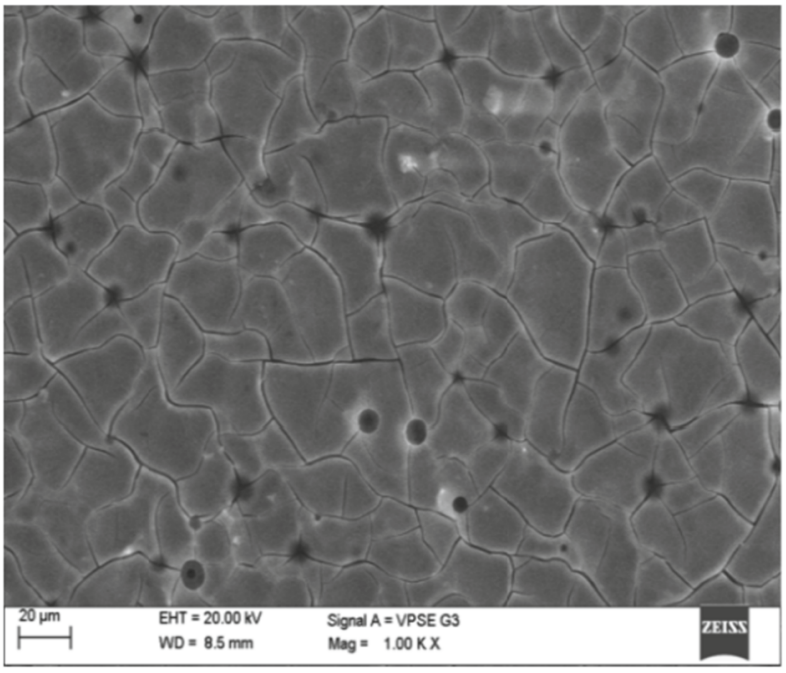

(b)

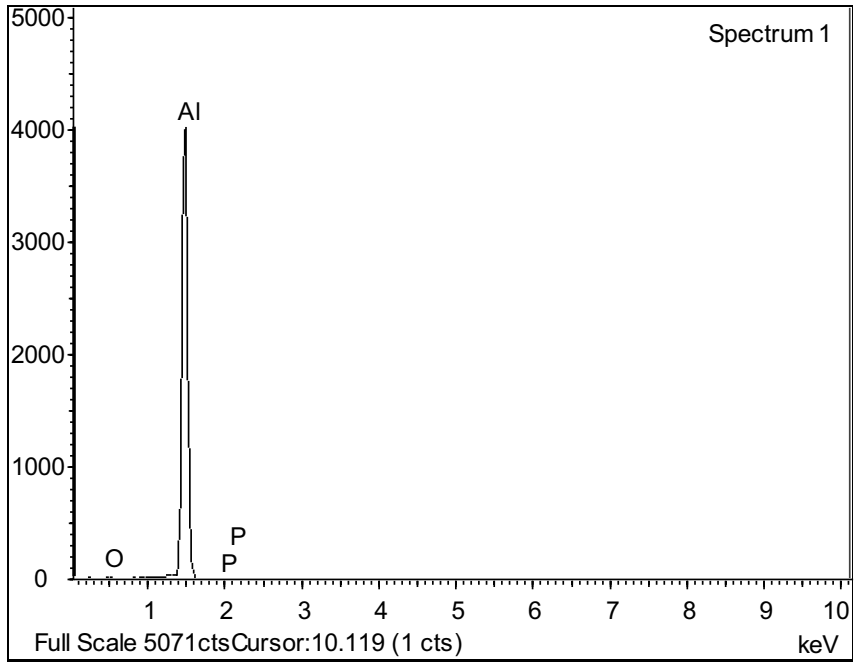

Fig. 8 a SEM b EDXS spectra of aluminum in the presence of $1.0 \mathrm{M} \mathrm{H}_{3} \mathrm{PO}_{4}$

(a)

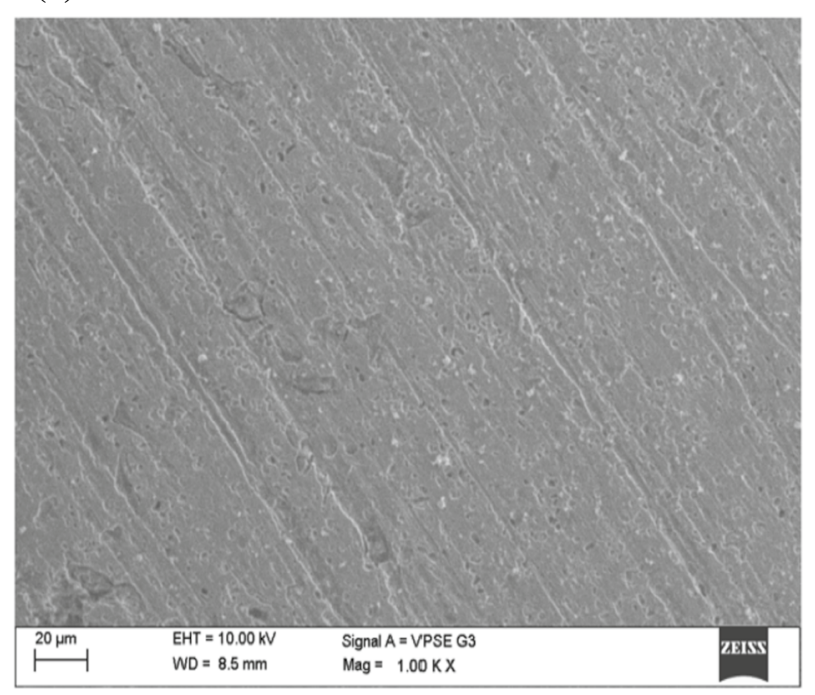

(b)

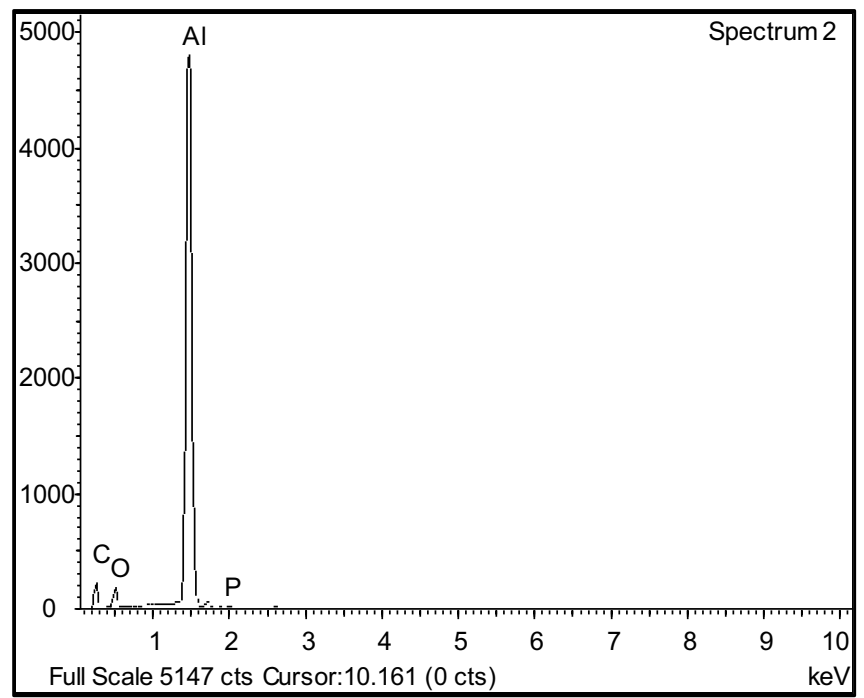

Fig. 9 a SEM b EDXS spectra of aluminum in the presence of $1.0 \mathrm{M} \mathrm{H}_{3} \mathrm{PO}_{4}$ with TCE (500 ppm)

$\mathrm{Al}$ immersed in $1.0 \mathrm{M} \mathrm{H}_{3} \mathrm{PO}_{4}$ and $1.0 \mathrm{M} \mathrm{H}_{3} \mathrm{PO}_{4}$ comprising TCE are given in Fig. 10a and Fig. 10b, respectively. It is observed that the roughness of the surface of samples in contact with $1.0 \mathrm{M} \mathrm{H}_{3} \mathrm{PO}_{4}$ corrosive was higher when compared to the sample surface after inhibition. The higher value of roughness before corrosion inhibition can be attributed to the higher corrosion tendency of $\mathrm{Al}$ in $1.0 \mathrm{M} \mathrm{H}_{3} \mathrm{PO}_{4}$. The value of Maximum Roughness Depth $\left(R_{\max }\right)$ dropped from 2193 to 1287 after the addition of $500 \mathrm{ppm}$ of TCE. This confirmed the film-forming ability of the TCE on the surface of the metal. Results of AFM measurements are tabulated in Table 4.

\section{Optimization of parameters for IE}

Screening tests uncovered that temperature, the concentration of TCE inhibitor, and concentration of acid notably affected the corrosion current density $\left(i_{\text {corr }}\right)$. Consequently, they were selected as investigation factors for further examination. The impact of temperature (A), the concentration of 

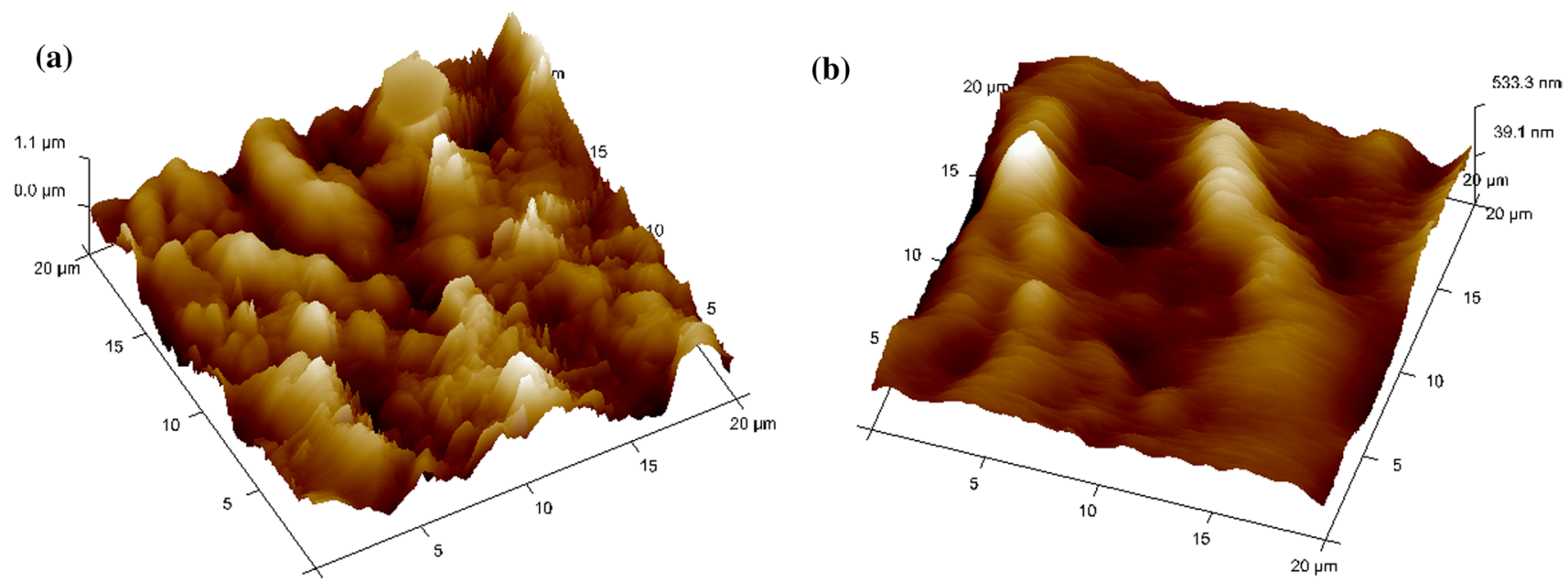

Fig.10 a AFM 3-D image of aluminum in $1.0 \mathrm{M} \mathrm{H}_{3} \mathrm{PO}_{4}$ and $\mathbf{b}$ aluminum in $1.0 \mathrm{M} \mathrm{H}_{3} \mathrm{PO}_{4}$ with TCE (500 ppm)

Table 4 AFM data obtained for aluminum in $1.0 \mathrm{M} \mathrm{H}_{3} \mathrm{PO}_{4}$ with $500 \mathrm{ppm}$ of TCE

\begin{tabular}{lll}
\hline Specimens & $R_{\mathrm{a}}(\mathrm{nm})$ & $R_{\max }(\mathrm{nm})$ \\
\hline $\mathrm{Al}$ in $1.0 \mathrm{M} \mathrm{H}_{3} \mathrm{PO}_{4}$ & 266 & 2193 \\
$\mathrm{Al}$ in $1.0 \mathrm{M} \mathrm{H}_{3} \mathrm{PO}_{4}+500 \mathrm{ppm}$ & 97.3 & 1287 \\
$\mathrm{TCE}$ & & \\
\hline
\end{tabular}

TCE inhibitor (B), and concentration of $\mathrm{H}_{3} \mathrm{PO}_{4}(\mathrm{C})$ were found by strategies for a CCD (Bingöl and Zor 2013). All the exploratory trials were executed arbitrarily to avoid regular slip-ups, and the results were then evaluated applying Minitab-19 programming (State College, PA: Minitab 2019). The arrangement of examination and the settings of the individual elements are given in Table 5 as coded esteems
Table 5 Experimental plan of design and their settings

\begin{tabular}{llllllll}
\hline Expt. run & \multicolumn{3}{l}{$\begin{array}{l}\text { Coded level of the } \\
\text { parameter }\end{array}$} & & $\begin{array}{l}\text { Corrosion current } \\
\text { density, } i_{\text {corr }}\end{array}$ & IE $(\%)$ & Residual \\
\cline { 2 - 4 } & $A$ & $B$ & $C$ & & Experimental & Predicted & \\
\hline 1 & 40 & 300 & 1.25 & 0.19 & 57.79 & 57.86 & 0.07 \\
2 & 30 & 500 & 2.00 & 0.08 & 78.04 & 78.04 & 0.00 \\
3 & 40 & 300 & 1.25 & 0.19 & 57.79 & 57.86 & 0.07 \\
4 & 40 & 300 & 1.25 & 0.19 & 57.79 & 57.86 & 0.07 \\
5 & 50 & 100 & 0.50 & 0.27 & 42.98 & 42.99 & 0.01 \\
6 & 50 & 500 & 0.50 & 0.17 & 64.23 & 64.15 & 0.08 \\
7 & 40 & 300 & 0.50 & 0.10 & 62.21 & 61.95 & 0.26 \\
8 & 40 & 300 & 1.25 & 0.19 & 57.79 & 57.86 & 0.07 \\
9 & 30 & 300 & 1.25 & 0.09 & 68.76 & 68.32 & 0.44 \\
10 & 30 & 500 & 0.50 & 0.03 & 83.24 & 83.28 & 0.04 \\
11 & 50 & 300 & 1.25 & 0.43 & 47.89 & 48.05 & 0.16 \\
12 & 40 & 500 & 1.25 & 0.15 & 69.45 & 69.33 & 0.12 \\
13 & 40 & 300 & 2.00 & 0.27 & 56.77 & 56.75 & 0.02 \\
14 & 40 & 100 & 1.25 & 0.24 & 49.54 & 49.35 & 0.19 \\
15 & 50 & 100 & 2.00 & 0.69 & 37.88 & 37.85 & 0.03 \\
16 & 30 & 100 & 0.50 & 0.06 & 64.40 & 64.57 & 0.17 \\
17 & 50 & 500 & 2.00 & 0.45 & 59.25 & 59.10 & 0.15 \\
18 & 40 & 300 & 1.25 & 0.19 & 57.79 & 57.86 & 0.07 \\
19 & 40 & 300 & 1.25 & 0.19 & 57.79 & 57.86 & 0.07 \\
20 & 30 & 100 & 2.00 & 0.15 & 59.15 & 59.24 & 0.09 \\
\hline & & & & & & &
\end{tabular}


alongside the corrosion current density. The IE was, moreover, acquired from polarization results, using the accompanying condition (Eq. 7):

$\operatorname{IE}(\%)=\frac{i_{\text {corr }}-i_{\text {corr }(\mathrm{inh})}}{i_{\text {corr }}} \times 100$,

where $i_{\text {corr }}$ and $i_{\text {corr (inh) }}$ are the corrosion current densities of blank and inhibited solutions.

From Table 5, it has been seen that the most elevated effectiveness is achieved in the trial with a TCE concentrate of $500 \mathrm{ppm}$, the concentration of $\mathrm{H}_{3} \mathrm{PO}_{4}$ of $0.5 \mathrm{M}$, and an operating temperature of $30{ }^{\circ} \mathrm{C}$. From the results, it is also seen that with the increase in the concentration of TCE inhibitor, the $i_{\text {corr }}$ value diminished. The multivariate regression empirical formula between IE and process factors was then established as shown in the following equation (Eq. 8): shows that $78 \%$ of the model process factors are significantly affecting the response. The results from the ANOVA exhibited that the temperature and concentration of TCE inhibitor are having a critical effect, with the impact of $47.89 \%$ and $46.85 \%$. Figure 11 represents a Pareto chart for $\mathrm{Al}$ in the $\mathrm{H}_{3} \mathrm{PO}_{4}$ solution which suggests that all the linear and square effects of the process parameters are having a significant effect on the response except the two-way interaction parameters (the same can be observed from the Table 6).

\section{Validation of the model}

Table 5 also demonstrates the anticipated IE against the IE, which was obtained experimentally. The analysis gave $R^{2}$ of 0.9998 and adjusted- $R^{2}$ of 0.9996 , which are very close to one, in this way, showing a generally decent relationship

$I E(\%)=104.39-1.371 \times A+0.01534 \times B-10.364 \times C+0.00323 \times A \times A+0.000037 \times B \times B+$

$2.645 \times C \times C+0.000306 \times A \times B+0.00617 \times A \times C+0.000142 \times B \times C$,

To locate a decent understanding of Analysis of Variance (ANOVA), the impact of factors at each level and the sum of squares (SS) and relating computations need further illustration. During the study, the level of significance is taken as $5 \%$. The estimation of $\mathrm{P}$ specifies whether the influence of that term is noteworthy or not (Asghari et al. 2016). From Table 6 , it is seen that for most of the cases, the $P$ value is 0.000 . A P-esteem under 0.05 demonstrates that the full quadratic model is the right model for this setting. Seven of the nine P-estimations of the model are under 0.05 , which between the anticipated and test estimations of the IE. Additionally, a very minimum deviation was observed between the experimental and predicted IE, which demonstrates that there is a good fit between them.

The performance of the influence of three factors measured separately on IE is presented in Fig. 12. From Fig. 12, it is seen that there was a decrease in IE when the temperature was increased from $30{ }^{\circ} \mathrm{C}$ to $50{ }^{\circ} \mathrm{C}$. The increase in temperature prompts an increment of the dynamic vitality for the inhibitor particles. This raises the pace of their crash

Table 6 ANOVA for IE for $\mathrm{Al}$ in $\mathrm{H}_{3} \mathrm{PO}_{4}$ solution

\begin{tabular}{|c|c|c|c|c|c|}
\hline Source & DF & Adj SS & Adj MS & $F$ value & $P$ value \\
\hline Model & 9 & 2144.87 & 238.32 & 5630.86 & 0.000 \\
\hline Linear & 3 & 2100.04 & 700.01 & $16,539.48$ & 0.000 \\
\hline Temperature & 1 & 1027.38 & 1027.38 & $24,274.46$ & 0.000 \\
\hline Concentration of TCE inhibitor & 1 & 1005.21 & 1005.21 & $23,750.44$ & 0.000 \\
\hline Concentration of $\mathrm{H}_{3} \mathrm{PO}_{4}$ & 1 & 67.44 & 67.44 & 1593.53 & 0.000 \\
\hline Square & 3 & 41.82 & 13.94 & 329.40 & 0.000 \\
\hline Temperature-temperature & 1 & 0.29 & 0.29 & 6.77 & 0.026 \\
\hline Concentration of TCE inhibitor-concentration of TCE inhibitor & 1 & 6.13 & 6.13 & 144.78 & 0.000 \\
\hline Concentration of $\mathrm{H}_{3} \mathrm{PO}_{4}$-concentration of $\mathrm{H}_{3} \mathrm{PO}_{4}$ & 1 & 6.09 & 6.09 & 143.81 & 0.000 \\
\hline Two-way interaction & 3 & 3.01 & 1.00 & 23.70 & 0.000 \\
\hline Temperature-concentration of TCE inhibitor & 1 & 2.99 & 2.99 & 70.62 & 0.000 \\
\hline Temperature-concentration of phosphoric acid & 1 & 0.02 & 0.02 & 0.40 & 0.539 \\
\hline Concentration of TCE inhibitor-concentration of $\mathrm{H}_{3} \mathrm{PO}_{4}$ & 1 & 0.00 & 0.00 & 0.09 & 0.776 \\
\hline Error & 10 & 0.42 & 0.04 & & \\
\hline Lack-of-fit & 5 & 0.42 & 0.08 & - & - \\
\hline Pure error & 5 & 0.00 & 0.00 & & \\
\hline Total & 19 & 2145.29 & & & \\
\hline
\end{tabular}


Fig. 11 Pareto chart of the standardized effects of parameters for $\mathrm{Al}$ in $\mathrm{H}_{3} \mathrm{PO}_{4}$
Pareto Chart of the Standardized Effects

(response is IE (\%), $\alpha=0.05$ )

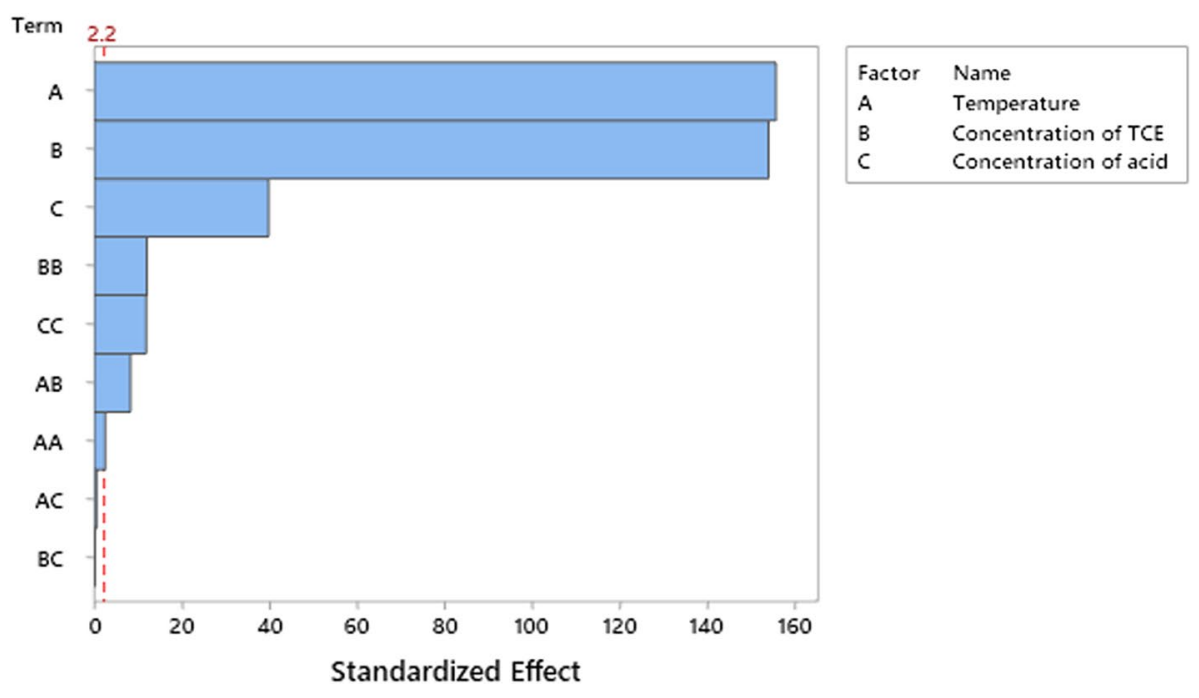

Main Effects Plot for IE (\%) Data Means

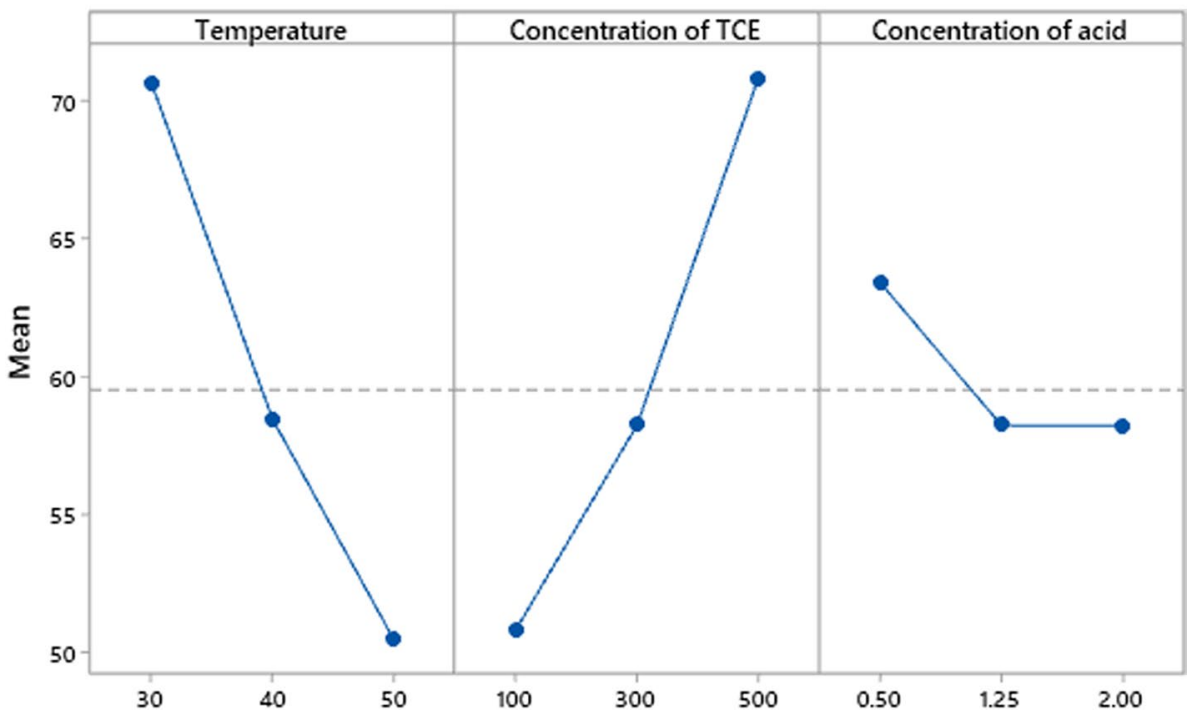

Fig. 12 Main effects plot for IE for $\mathrm{Al}$ in $\mathrm{H}_{3} \mathrm{PO}_{4}$ with one another. This accordingly blocks and eases back the arrangement of the protective film of inhibitors on the surface of the metal. The increase in temperature causes a decrease in the adsorption process of inhibitor on the surface of the metal. A similar trend was observed with the concentration of $\mathrm{H}_{3} \mathrm{PO}_{4}$ when it was increased from $0.5 \mathrm{M}$ to $2.0 \mathrm{M}$. Whereas the relationship between the concentration of TCE inhibitor and IE has an inverse relationship. The IE increased when the concentration of TCE inhibitor was increased from 100 to $500 \mathrm{ppm}$. The corrosion rate was the most elevated without inhibitor arrangement, and afterward, it begins to decline when the inhibitor being included until it becomes stable toward the finish of examination.
However, IE increases with the increase of concentration of TCE inhibitor. The concentration of inhibitor rise prompts both the adsorption and surface inclusion rise, and along these lines, this developing leads to lessen the corrosion rate and increase the IE.

The collaboration between variables happens when the change in response is distinctive for two factors. In the interaction plot, if there is any interaction, they are represented by crossed lines. If the lines are straight/parallel, then there is no interaction among the factors. Figure 13 shows the interaction effect plot for IE recommends that the interaction between the variables is not exceptionally noteworthy. From the ANOVA investigation, it is additionally observed that 
Fig. 13 Interaction effect plot for IE for $\mathrm{Al}$ in $\mathrm{H}_{3} \mathrm{PO}_{4}$
Interaction Plot for IE (\%)

Data Means

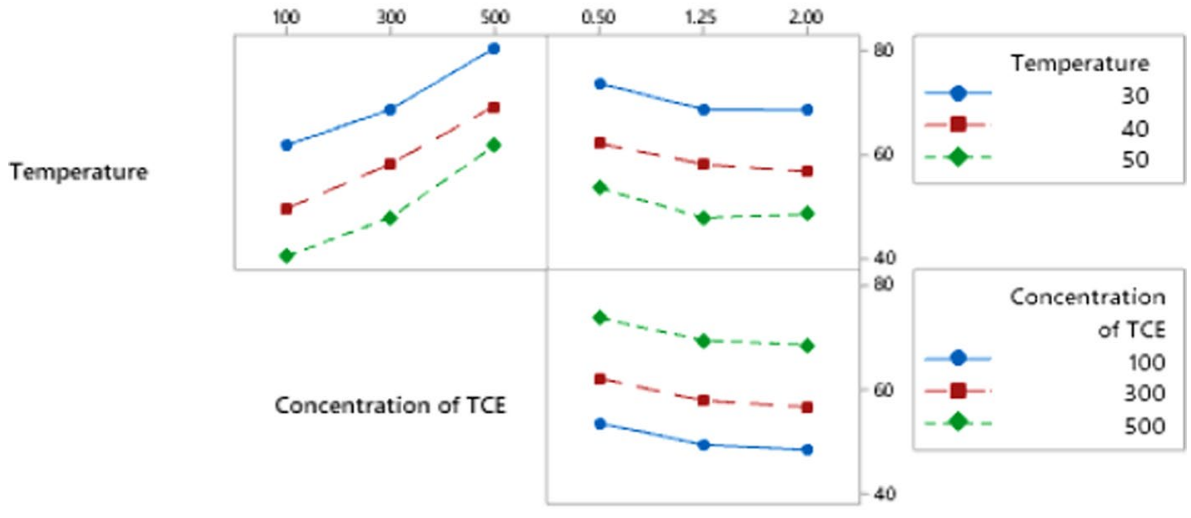

Concentration of acid

two-way interactions among the factors are not considered as the value of $P$ is higher than 0.05 ; showing there is no connection among the concentration of TCE inhibitor, the concentration of $\mathrm{H}_{3} \mathrm{PO}_{4}$, and temperature.

\section{Optimization of response}

Numerical streamlining of the model in Eq. (8) was done to decide the concentration of TCE inhibitor, the concentration of $\mathrm{H}_{3} \mathrm{PO}_{4}$, and temperature at which the corrosion rate of aluminum was at least with the goal that it will bring about highest IE. The DFA was utilized to enhance the process factors for the most noteworthy conceivable response. In the first place, the objective components for temperature, the concentration of TCE inhibitor, and concentration of $\mathrm{H}_{3} \mathrm{PO}_{4}$ were set, while that of IE was set to "most extreme". The response optimization plot for IE is shown in Fig. 14. From the plot, the anticipated ideal elements were evaluated to be temperature $\left(30{ }^{\circ} \mathrm{C}\right)$, and concentration of TCE inhibitor (500 ppm), and concentration of $\mathrm{H}_{3} \mathrm{PO}_{4}$ of $0.5 \mathrm{M}$. At these ideal conditions, the comparing anticipated IE was seen as $83.35 \%$. Affirmation tests were likewise directed to approve the ideal parameter settings and to confirm the improvement of the IE. The reason for affirmation tests is to check the redundancy of the exploratory outcomes and approve the exactness of the prescient model.

\section{Mechanism of inhibition}

The charge on the metal-solution interface is dependent on solution $\mathrm{pH}$. In the presence of an acid, the surface charge of $\mathrm{Al}$ is due to the interaction of the oxygen atoms of the surface with water developing $\mathrm{M}-\mathrm{OH}$. Hydroxylated sites (Al-OH) acquire positive charged by reacting with the proton of acid $\left(\mathrm{H}^{+}\right)$. These surface charges initiate the adsorption of negatively charged ions from the electrolyte. The TCE consists of a large number of compounds. The principal components are reported in Sect. 3.1. The structures of these components are given in Fig. 15.

Fig. 14 Response optimization plot for IE

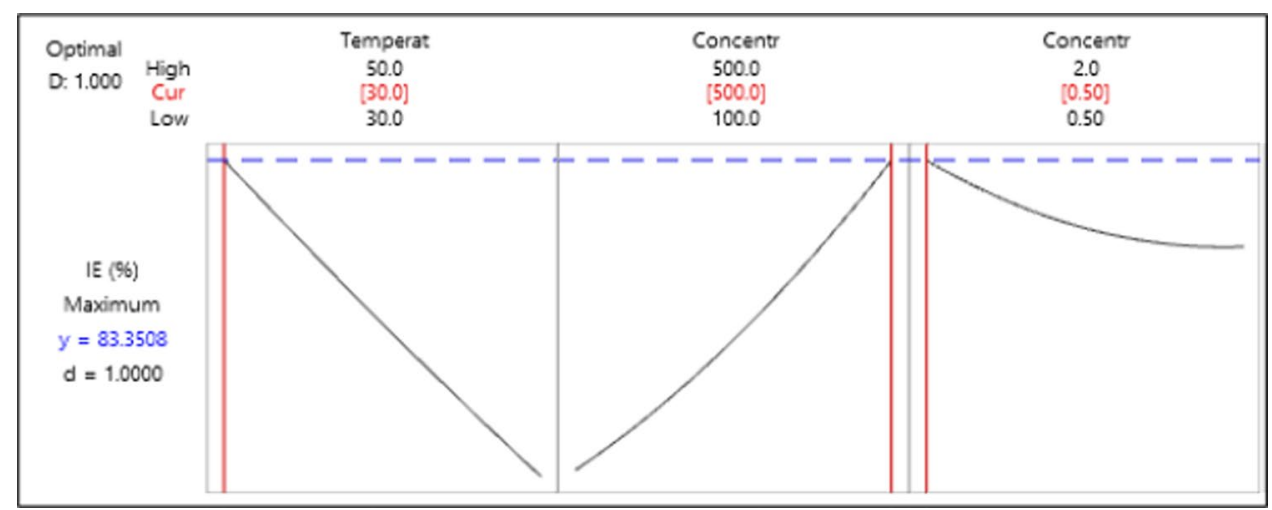


Fig. 15 Structure of components of Terminalia chebula<smiles>O=C(OC[C@H]1O[C@H](OC(=O)c2cc(O)c(O)c(O)c2)[C@H](OC(=O)c2cc(O)c(O)c(O)c2)[C@H](OC(=O)c2cc(O)c(O)c(O)c2)[C@@H]1OC(=O)c1cc(O)c(O)c(O)c1)c1cc(O)c(O)c(O)c1</smiles>

1,2,3,4,6-Pentagalloyl glucose

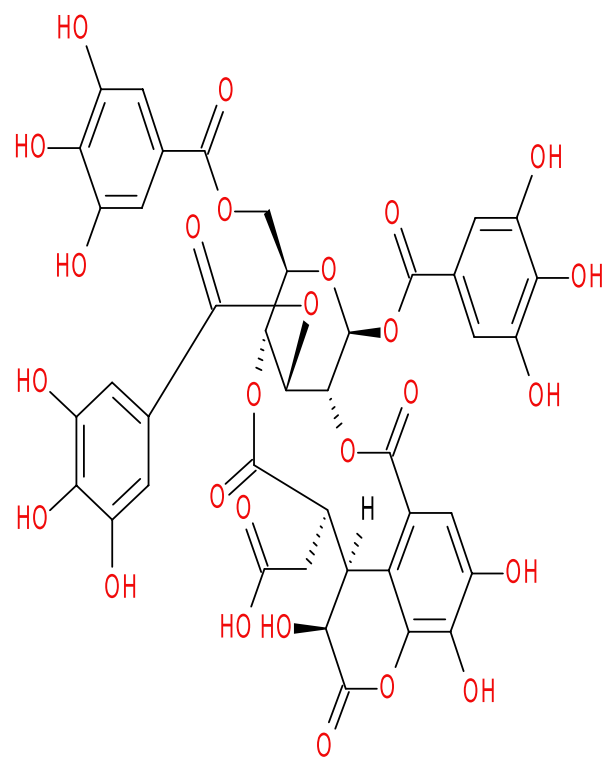

Chebulinic acid
The inhibitor structures are protonated at the $\mathrm{OH}$ terminal in the presence of acid. These protonated inhibitor molecules become attracted to phosphate layer (negatively charged) and thus get physically adsorbed on the surface of Al, as shown in Eq. 9: decreased with an increase in temperature as well as with an increase in concentrations of $\mathrm{H}_{3} \mathrm{PO}_{4}$.

Langmuir adsorption isotherm was followed and the adsorption of TCE was physisorption.

The surface analysis results were complementing the

$$
\mathrm{A} 1-\mathrm{OH}_{2}^{+} \rightarrow \mathrm{A} 1-\mathrm{OH}_{2}^{+}-\mathrm{PO}_{4 \text { (ads) }}^{3-} \rightarrow \mathrm{OH}_{2}^{+}-\mathrm{PO}_{4(\mathrm{ads})}^{3-}-(\mathrm{Inh})_{(\mathrm{ads})}^{+} \text {, }
$$

Due to the relatively larger size of the molecule, the protective film of the inhibitor covers the entire surface of the metal. It results in a barrier formed between the $\mathrm{Al}$ and acid medium. This is largely attributed to the bulky size and the large number of - $\mathrm{OH}$ groups of components of TCE, which are covering the metal surface thus reducing the corrosion reaction.

\section{Conclusions}

In this investigation, PDP and RSM techniques were utilized to identify the inhibition efficiency of aluminum as an element of the working factors: temperature, the concentration of TCE inhibitor, and concentration of $\mathrm{H}_{3} \mathrm{PO}_{4}$.

The inhibition efficiency of TCE increased with an increase in the concentrations of the inhibitors, and obtained data and justified the adsorption phenomena. Analysis of variance showed that the model was profoundly significant, and temperature and concentration of TCE inhibitor were found to be the two most significant factors with a contribution of $47.89 \%$ and $46.85 \%$, affecting the corrosion of $\mathrm{Al}$, thereby increasing the inhibition efficiency.

High values of $R^{2}(0.9998)$ and adjusted- $R^{2}(0.9996)$ indicated a good correlation between the predicted and experimental values.

In boosting the inhibition efficiency, the ideal working conditions were acquired at a temperature of $30{ }^{\circ} \mathrm{C}$, inhibitor concentration of $500 \mathrm{ppm}$, and acid concentration of $\mathrm{H}_{3} \mathrm{PO}_{4}$ of $0.5 \mathrm{M}$.

In this way, it is evident that RSM not just gives a critical understanding of the interaction between the variables, yet also helps to identify the optimum parameter setting for the same. 
Funding Open access funding provided by Manipal Academy of Higher Education, Manipal.

\section{Compliance with ethical standards}

Conflict of interest On behalf of all authors, the corresponding author states that there is no conflict of interest.

Open Access This article is licensed under a Creative Commons Attribution 4.0 International License, which permits use, sharing, adaptation, distribution and reproduction in any medium or format, as long as you give appropriate credit to the original author(s) and the source, provide a link to the Creative Commons licence, and indicate if changes were made. The images or other third party material in this article are included in the article's Creative Commons licence, unless indicated otherwise in a credit line to the material. If material is not included in the article's Creative Commons licence and your intended use is not permitted by statutory regulation or exceeds the permitted use, you will need to obtain permission directly from the copyright holder. To view a copy of this licence, visit http://creativecommons.org/licenses/by/4.0/.

\section{References}

Ajeigbe SO, Basar N, Hassan MA, Aziz M (2017) Optimization of corrosion inhibition of essential oils of alpinia galanga on mild steel using response surface methodology. ARPN J Eng Appl Sci 12(9):2763-2771

Alaba AO, Odejobi OJ, Odekanle EL (2020) Thermodynamics and adsorption study of the corrosion inhibition of mild steel by Euphorbia Heterophylla L. extract in $15 \mathrm{M} \mathrm{HCl}$. Results Mater 5:100074. https://doi.org/10.1016/j.rinma.2020.100074

Asghari E, Ashassi-Sorkhabi H, Ahangari M, Bagheri R (2016) Optimization of a three-component green corrosion inhibitor mixture for using in cooling water by experimental design. J Mater Eng Perform 25(4):1416-1425. https://doi.org/10.1007/ s11665-015-1865-7

Barthakur NN, Arnold NP (1991) Nutritive value of the chebulic myrobalan (Terminalia Chebula Retz.) and Its potential as a food source. Food Chem 40(2):213-219. https://doi. org/10.1016/0308-8146(91)90105-W

Beg QK, Sahai V, Gupta R (2003) Statistical media optimization and alkaline protease production from bacillus mojaensis in a bioreactor. Proc Biochem 39(2):203-209

Benabbouha T, Nmila R, Siniti M, Chefira K, El Attari H, Rchid H (2020) The brown algae cystoseira baccata extract as a friendly corrosion inhibitor on carbon steel in acidic media. SN Appl Sci 2(4):662. https://doi.org/10.1007/s42452-020-2492-y

Bingöl D, Zor S (2013) Optimization of the experimental variables influencing the corrosion rate of aluminum using response surface methodology. Corrosion 69(5):462-467. https://doi. org $/ 10.5006 / 0382$

Chen S, Liang X, Zhu B (2020) corrosion inhibition performance of coconut leaf extract as a green corrosion inhibitor for X65 Steel in hydrochloric acid solution. Int J Electrochem Sci 15:1-15

Demirel M, Kayan B (2012) Application of response surface methodology and central composite design for the optimization of textile dye degradation by wet air oxidation. Internat J Ind Chem 3(1):24. https://doi.org/10.1186/2228-5547-3-24

Fakhri A, Adami S (2013) Response surface methodology for adsorption of fluoride ion using nanoparticle of Zero Valent Iron from aqueous solution. J Chem Eng Proc Technol 4(5):1-6

Fallavena T, Antonow M, Gonçalves RS (2006) Caffeine as nontoxic corrosion inhibitor for copper in aqueous solutions of potassium nitrate. Appl Surf Sci 253(2):566-571. https://doi. org/10.1016/J.APSUSC.2005.12.114

Fatima B, Labjar N, Abdoun F, Mazkour A, Serghini-Idrissi M, El Mahi M, Lotfi EM, El Hajjaji S (2020) "Electrochemical and thermodynamic investigation on corrosion inhibition of C38 Steel in $1 \mathrm{M}$ hydrochloric acid using the hydro-alcoholic extract of used coffee grounds" Edited by Ramazan Solmaz. Internat J Corros 2:4045802. https://doi.org/10.1155/2020/4045802

Fouda AS, Al-Sarawy AA, Ahmed FSh, El-Abbasy HM (2009) Corrosion inhibition of aluminum 6063 using some pharmaceutical compounds. Corros Sci 51(3):485-492. https://doi. org/10.1016/J.CORSCI.2008.10.012

Fouda AS, Abdallah M, Ahmed IS, Eissa M (2012) Corrosion inhibition of aluminum in $1 \mathrm{M} \mathrm{H} 3 \mathrm{PO} 4$ solutions by ethanolamines. Ar J Chem 5(3):297-307. https://doi.org/10.1016/J.ARABJ C.2010.08.020

Fouda AS, El-shereafy EE, Hathoot AA, El-bahrawi NM (2020) Corrosion inhibition of aluminum by cerumium rubrum extract in hydrochloric acid environment. J Bio Tribo Corros 6(2):37. https://doi.org/10.1007/s40735-020-0330-9

Gao G, Liang C (2007) Electrochemical and DFT studies of $\beta$-Amino-Alcohols as corrosion inhibitors for brass. Electrochim Acta 52(13):4554-4559. https://doi.org/10.1016/J.ELECT ACTA.2006.12.058

Gapsari F, Soenoko R, Suprapto A, Suprapto W (2018) Minimization of corrosion rate using response surface methodology. Eng Rev 38(1):115-119

Giacomelli FC, Giacomelli C, Amadori MF, Schmidt V, Spinelli A (2004) Inhibitor effect of succinic acid on the corrosion resistance of mild steel: electrochemical, gravimetric and optical microscopic studies. Mater Chem Phys 83(1):124-128. https:// doi.org/10.1016/J.MATCHEMPHYS.2003.09.013

Heragh F (2019) Electrochemical properties of a new green corrosion inhibitor derived from prosopis farcta for St37 steel in $1 \mathrm{M}$ hydrochloric acid. Met Mater Int. https://doi.org/10.1007/s1254 0-019-00453-6

Izionworu VO, Ukpaka CP, Oguzie EE (2020) Green and eco-benign corrosion inhibition agents: alternatives and options to chemical based toxic corrosion inhibitors. Chem Internat 6(4):232-259

Jeirani Z, Mohamed Jan B, Si Ali B, Noor IM, See CH, Saphanuchart W (2013) Prediction of the optimum aqueous phase composition of a triglyceride microemulsion using response surface methodology. J Ind Eng Chem 19(4):1304-1309. https://doi.org/10.1016/j. jiec.2012.12.032

José F, González A (1989) Corrosion Control study and measurement by electrochemical techniques. Higher Council for Scientific Research, Madrid

Li X, Deng S (2012) Inhibition effect of dendrocalamus brandisii leaves extract on aluminum in $\mathrm{HCl}, \mathrm{H} 3 \mathrm{PO} 4$ solutions. Corros Sci 65:299-308. https://doi.org/10.1016/J.CORSCI.2012.08.033

Li X, Deng S, Hui Fu (2011) Sodium molybdate as a corrosion inhibitor for aluminium in H3PO4 solution. Corros Sci 53(9):27482753. https://doi.org/10.1016/J.CORSCI.2011.05.002

Lin CC, Lin CS (2012) "Phytochemical composition, antioxidant activity, and neuroprotective effect of terminalia chebula retzius extracts" Edited by Boli Zhang. Evid Based Comple Alternat Med 2:125247. https://doi.org/10.1155/2012/125247

Lowmunkhong P, Ungthararak D, Sutthivaiyakit P (2010) Tryptamine as a corrosion inhibitor of mild steel in hydrochloric acid solution. Corros Sci 52(1):30-36. https://doi.org/10.1016/j.corsc i.2009.08.039

Maher T, Al-Shamkhani AA (2018) Use of experimental designs to evaluate the influence of ziziphus leaves extracts as a corrosion inhibitor for mild steel in (3.5M) NaCl. Internat J Appl Eng Res 13(10):7416-7423 
Minitab I (2019) MINITAB Release 17: Statistical Software for Windows. Minitab Inc., State College, PA, USA

Mizuno K, Nylund A, Olefjord I (2001) Surface reactions during pickling of an aluminium-magnesium-silicon alloy in phosphoric acid. Corros Sci 43(2):381-396. https://doi.org/10.1016/S0010 $-938 X(00) 00069-X$

Moretti G, Guidi F, Grion G (2004) Tryptamine as a green iron corrosion inhibitor in $0.5 \mathrm{M}$ deaerated sulphuric acid. Corros Sci 46(2):387-403. https://doi.org/10.1016/S0010-938X(03)00150-1

Nathan CC, National Association of Corrosion Engineers (1973). Corrosion Inhibitors. Nat Assoc Corros Eng. https://books.google.co. in/books?id=Bb5RAAAAMAAJ. Accessed 26 Jan 2020

Oguzie EE, Njoku VO, Enenebeaku CK, Akalezi CO, Obi C (2008) Effect of hexamethylpararosaniline chloride (Crystal Violet) on mild steel corrosion in acidic media. Corros Sci 50(12):3480 3486. https://doi.org/10.1016/j.corsci.2008.09.017

Omoruwou F, Okewale AO, Owabor CN (2017) Statistical analysis of corrosion inhibition of water hyacinth on mild steel in an acidic medium. J Environ Anal Toxicol 7(4):481

Prabhu D, Rao P (2013) Coriandrum Sativum L. - a novel green inhibitor for the corrosion inhibition of aluminium in $1.0 \mathrm{~m}$ phosphoric acid solution. J Environ Chem Eng 1(4):676-683. https://doi. org/10.1016/j.jece.2013.07.004

Prabhu D, Rao P (2019) A comparative study on inhibitory actions of TCE, GIE, and CSE on the corrosion of $6063 \mathrm{Al}$ alloy in H3PO4 medium. J Bio Tribo-Corros 5(3):76. https://doi.org/10.1007/ s40735-019-0269-x

Prabhu PR, Prabhu D, Rao P (2020a) Optimization of the parameters influencing the inhibition efficiency of $6063 \mathrm{Al}$ Alloy in $0.5 \mathrm{M}$ $\mathrm{NaOH}$ using response surface methodology. Internat J Mech Prod Eng Res Deve 10(2):51-64. https://doi.org/10.24247/ijmperdapr 20205

Prabhu PR, Prabhu D, Rao P (2020b) Analysis of garcinia indica choisy extract as eco-friendly corrosion inhibitor for aluminum in phosphoric acid using the design of experiment. J Mater Res Technol. https://doi.org/10.1016/J.JMRT.2020.01.100

Rashid KH, Khadom AA (2019) Optimization of inhibitive action of sodium molybdate (VI) for corrosion of carbon steel in saline water using response surface methodology. Korean J Chem Eng 36(8):1350-1359. https://doi.org/10.1007/s11814-019-0291-1

Şahin EA, Solmaz R, Gecibesler İH, Kardaş G (2020) Adsorption ability, stability and corrosion inhibition mechanism of phoenix dactylifera extrat on mild steel. Mater Res Exp 7(1):16585. https ://doi.org/10.1088/2053-1591/ab6ad3

Santos AM, Aquino IP, Cotting F, Aoki IV, de Melo HG, Capelossi VR (2020) Evaluation of palm kernel cake powder (Elaeis Guineensis Jacq) as corrosion inhibitor for carbon steel in acidic media. Met Mater Internat. https://doi.org/10.1007/s12540-019-00559-x
Saxena A, Sharma V, Thakur KK, Bhardwaj N (2020) Electrochemical studies and the surface examination of low carbon steel by applying the extract of citrus sinensis. J Bio Tribo Corros 6(2):41. https ://doi.org/10.1007/s40735-020-00338-x

Sedik A, Lerari D, Salci A, Athmani S, Bachari K, Gecibesler İH, Solmaz R (2020) Dardagan fruit extract as eco-friendly corrosion inhibitor for mild steel in $1 \mathrm{M} \mathrm{HCl}$ : electrochemical and surface morphological studies. J Taiwan Instit Chem Eng. https://doi. org/10.1016/J.JTICE.2019.12.006

Shinato KW, Zewde AA, Jin Y (2020) Corrosion protection of copper and copper alloys in different corrosive medium using environmentally friendly corrosion inhibitors. Corros Rev 38(2):101-109. https://doi.org/10.1515/corrrev-2019-0105

Solomon MM, Umoren SA, Udosoro II, Udoh AP (2010) Inhibitive and adsorption behaviour of carboxymethyl cellulose on mild steel corrosion in sulphuric acid solution. Corros Sci 52(4):1317-1325. https://doi.org/10.1016/J.CORSCI.2009.11.041

Tang L, Guannan Mu, Liu G (2003) The effect of neutral red on the corrosion inhibition of cold rolled steel in $10 \mathrm{M}$ hydrochloric acid. Corros Sci 45(10):2251-2262. https://doi.org/10.1016/S0010 $-938 \mathrm{X}(03) 00046-5$

Tansuğ G, Tüken T, Kicir N, Erbil M (2014) Investigation of 2-aminoethanethiol as corrosion inhibitor for steel using response surface methodology (RSM). Ionics 20(2):287-294. https://doi. org/10.1007/s11581-013-0966-2

Tomas GG et al (2020) Evaluation of purple onion (Allium Cepa L.) extract as a natural corrosion inhibitor for carbon steel in acidic media. Meta Mater Internat. https://doi.org/10.1007/s12540-02000679-9

Udensi SC, Ekpe OE, Nnanna LA (2020) Newbouldia Laevis leaves extract as tenable eco-friendly corrosion inhibitor for aluminium alloy AA7075-T7351 in $1 \mathrm{M} \mathrm{HCl}$ corrosive environment: gravimetric, electrochemical and thermodynamic studies. Chem Africa. https://doi.org/10.1007/s42250-020-00131-w

Umoren SA, Solomon MM, Madhankumar A, Obot IB (2020) Exploration of natural polymers for use as green corrosion inhibitors for AZ31 magnesium alloy in saline environment. Carbohydr Poly 230:115466. https://doi.org/10.1016/j.carbpol.2019.115466

Yüce AO (2020) corrosion inhibition behavior of robinia pseudoacacia leaves extract as a eco-friendly inhibitor on mild steel in acidic media. Met Mater Int 26(4):456-466. https://doi.org/10.1007/ s12540-019-00509-7

Publisher's Note Springer Nature remains neutral with regard to jurisdictional claims in published maps and institutional affiliations. 